\title{
An acid-free route for the facile synthesis of iron-functionalized mesoporous silicas: Transformation between hollow nanospheres and cage-like mesostructures
}

\author{
Hongchuan Xin ${ }^{\mathrm{a}, \mathrm{b}}$, Jiao Zhao ${ }^{\mathrm{a}}$, Xiaobo $\mathrm{Li}^{\mathrm{a}}$, Jianting Tang ${ }^{\mathrm{a}}$, Qihua Yang ${ }^{\mathrm{a}, *}$ \\ a State Key Laboratory of Catalysis, Dalian Institute of Chemical Physics, Chinese Academy of Sciences, 457 Zhongshan Road, Dalian 116023, China \\ ${ }^{\mathrm{b}}$ Key Laboratory of Biofuels, Qingdao Institute of Bioenergy and Bioprocess Technology, Chinese Academy of Sciences, 189 Songling Road, Qingdao 266101, China
}

\section{A R T I C L E I N F O}

\section{Article history:}

Received 1 October 2013

Received in revised form 7 January 2014

Accepted 14 January 2014

Available online 27 January 2014

\section{Keywords:}

Acid-free

Iron

Mesoporous

Hollow nanospheres

FDU-12

\begin{abstract}
A B S T R A C T
Iron-substituted silicas with hollow nanospherical morphology and cage-like mesostructure have been synthesized using triblock copolymer F127 as surfactant and tetramethoxysilane (TMOS) as silica source with no necessary addition of mineral acids. Iron-functionalized hollow nanospheres were obtained using $\mathrm{Fe}(\mathrm{acac})_{3}$ as iron source. When $\mathrm{Fe}\left(\mathrm{NO}_{3}\right)_{3}$ was employed as iron source, iron-containing cage-like FDU-12 mesostructure and hollow nanospheres were formed with $\mathrm{Fe} / \mathrm{Si}$ molar ratio lower than 0.008 and higher than 0.015 , respectively. The formation of hollow spheres at high Fe/Si ratio can be regarded as gradually dissociation of nanocages from Fe-FDU-12. The structure of the iron centers was determined by spectroscopic methods (UV-vis and UV-Raman measurements) and by elemental analyses. The facile structural evolution between cage-like and nanospherical structures may be helpful for further understanding the formation mechanism of mesoporous silicas.
\end{abstract}

(c) 2014 Elsevier Inc. All rights reserved.

\section{Introduction}

Mesoporous silicas have attracted much attention in last decades due to their wide applications in adsorption, catalysis, and drug delivery [1-4]. Metal-containing mesoporous silicas are of great interest because these functionalized silicas are extremely attractive as catalysts for acid-base, redox, and alkylation reactions [5-7]. One-pot hydrothermal synthesis is preferred for the preparation of metal-substituted mesoporous silicas in the presence of structure-directing agents under acidic [8], neutral [9], or basic [10] conditions.

For transition-metal substituted mesoporous silicas, it is apparent that the transition metal center and the porous structure both play important roles in obtaining desirable properties. Attributed to the development in the material science, the silicas with different morphology and mesostructure have been successfully synthesized $[11,12]$. However, only limited attention has been paid to the structure and morphology control of the transition-metal substituted mesoporous silicas, partly due to the unmatched conditions for the incorporation of transition metal ions and the formation of silicas with controlled morphology and mesostructure. For example, the nonionic-surfactants (such as P123, F127) have been

\footnotetext{
* Corresponding author. Tel.: +86 411 84379552; fax: +86 41184694447 .

E-mail address: yangqh@dicp.ac.cn (Q. Yang).
}

widely used as templates for the fabrication of mesostructured silicas normally in strongly acidic conditions [13]. However, the highly acidic media are not ideal for incorporation of transitionmetal ions due to the high solubility of the $\mathrm{Si}-\mathrm{O}-\mathrm{M}$ species. The previous studies show that the mild reaction media may solve this problem [14-17], but the structural and morphological control of silicas in mild reaction medium is not well developed yet.

It is still a challenge to synthesize transition-metal functionalized mesoporous silicas with desirable active metal centers (such as highly isolated metal sites [18]) and architectures (such as spherical and cage-like pore structures). Among the silica fibers, spheres, rods and nanoparticles, the hollow nanospheres are very attractive, given that the hollow interior can encapsulate the guest molecules for wide application potentials [19-28]. The modification of the shell of the hollow nanospheres may further expand the application potentials of the hollow nanospheres [29-35]. The strategies for the synthesis of hollow silica-based nanospheres were already well reviewed [36,37], and can be categorized as: selective etching or dissolution, soft templating, self templating, galvanic replacement method, and Ostwald ripening method, etc. Based on the composition and structure, the obtained hollow nanospheres can be classified as pure siliceous nanospheres [38,39], phosphosilicate nanospheres [40], multi-shell silica nanospheres [32,41], organo-functionalized silica nanospheres [22,42], and yolk-shell nanoparticles [34,37], etc. Our group has developed an 

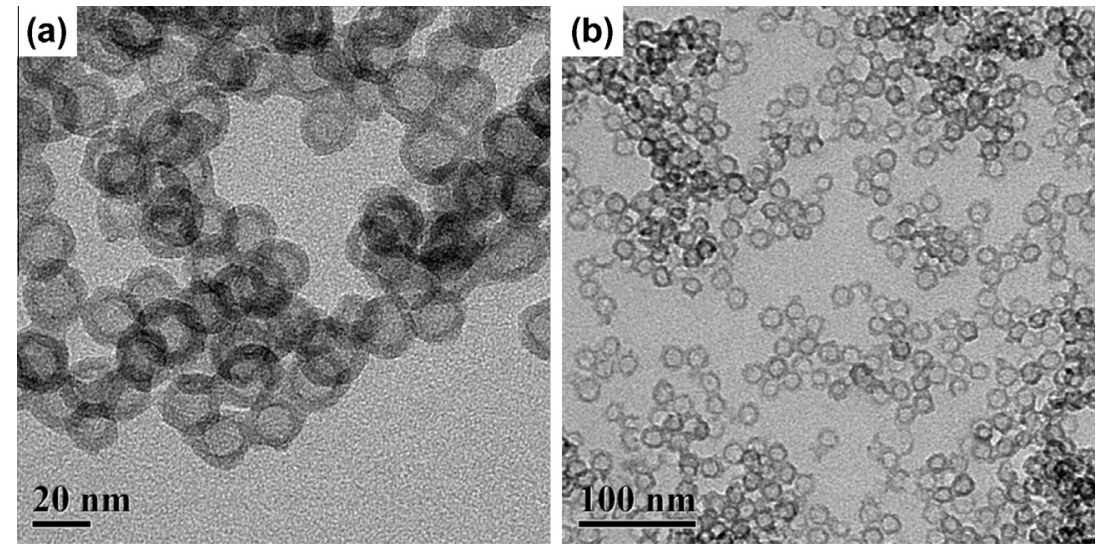

Fig. 1. TEM images of Fe-substituted hollow nanospheres: (a) NS-0.8 and (b) NS-1.5.

easy, convenient and efficient method for the green synthesis of hollow nanospheres in deionized water without any mineral acid addition [43]. The neutral synthesis medium may provide an opportunity for the effective incorporation of transition-metal ions in the shell of the hollow nanospheres.

To the best of our knowledge, the synthesis of transition metal ion-substituted hollow nanospheres via direct hydrothermal route has rarely been reported. In this study, based on our previous study [43], we report the facile synthesis of Fe-containing silica hollow nanospheres in acid-free neutral medium using F127 as the structure-directing agent. In addition, the evolution of hollow nanosphere to cage-like FDU-12 mesostructure was observed by simply varying the iron precursor and $\mathrm{Fe} / \mathrm{Si}$ molar ratio.

\section{Experimental sections}

\subsection{Reagents}

All materials were of analytical grade and used as received without any further purification. Pluronic F127 $\left(\mathrm{EO}_{106} \mathrm{PO}_{70} \mathrm{EO}_{106}\right)$ was purchased from Sigma-Aldrich Company Ltd. (USA). Tetramethoxysilane (TMOS), 1,3,5-trimethylbenzene (TMB), $\mathrm{Fe}\left(\mathrm{NO}_{3}\right)_{3} \cdot 9 \mathrm{H}_{2}$ $\mathrm{O}, \mathrm{Fe}(\mathrm{acac})_{3}$, and $\mathrm{K}_{2} \mathrm{SO}_{4}$ were obtained from Shanghai Chemical Reagent, Inc. of Chinese Medicine Group.

\subsection{Synthesis}

For the synthesis of Fe-substituted hollow nanospheres, F127 $(1.00 \mathrm{~g}), \mathrm{TMB}(1.00 \mathrm{~g})$, and $\mathrm{K}_{2} \mathrm{SO}_{4}(3.49 \mathrm{~g})$ were dissolved in water $(60 \mathrm{~mL})$, and the solution was stirred at $13.5^{\circ} \mathrm{C}$ for $2 \mathrm{~h}$. Desired amount of $\mathrm{Fe}(\mathrm{acac})_{3}$ dissolved in TMOS (3.04 g) was added to the above surfactant solution. After stirring at $13.5^{\circ} \mathrm{C}$ for $24 \mathrm{~h}$, the mixture was transferred into a Teflon-lined autoclave and aged at $100{ }^{\circ} \mathrm{C}$ for another $24 \mathrm{~h}$. The precipitate was filtered off, rinsed repeatedly with water and dried at $100{ }^{\circ} \mathrm{C}$. The as-synthesized sample was calcined in air at $550^{\circ} \mathrm{C}$ for $10 \mathrm{~h}$ with a ramp of $1{ }^{\circ} \mathrm{C} \min ^{-1}$. The calcined samples were denoted as NS- $n(n=0.8$ or 1.5), where $n$ is the mol\% of Fe/Si in the initial mixture.

$\mathrm{NO}_{3}$-NS- $n(n=0.8,1.5$, and 2.3) samples were synthesized using a method similar to NS- $n$ samples with slight variation. $\mathrm{Fe}\left(\mathrm{NO}_{3}\right)_{3}$ was used as iron source and the molar ratio of $\mathrm{H}_{2} \mathrm{O} / \mathrm{F} 127$ is 28000 (the $\mathrm{H}_{2} \mathrm{O} / \mathrm{F} 127$ molar ratio for NS- $n$ is 42000). The calcined samples were denoted as $\mathrm{NO}_{3}$-NS- $n(n=0.8,1.5$, and 2.3$)$, where $n$ is the $\mathrm{mol} \%$ of $\mathrm{Fe} / \mathrm{Si}$ in the initial mixture.

In order to investigate the role of TMB in the synthesis process, $\mathrm{NS}^{*}-0.8$ and $\mathrm{NO}_{3}-\mathrm{NS}^{*}-0.8$ were synthesized with the same procedures to NS-0.8 and $\mathrm{NO}_{3}-\mathrm{NS}-0.8$, respectively, except for the addition of TMB.

\subsection{Characterization}

X-ray diffraction (XRD) patterns were recorded on a Rigaku RINT D/Max-2500 powder diffraction system using $\mathrm{Cu} \mathrm{K} \alpha$ radiation of $0.15406 \mathrm{~nm}$ wavelength. The nitrogen sorption experiments were performed at $-196^{\circ} \mathrm{C}$ on a Micromeritics ASAP 2020 system. Prior to the measurement, the materials were out-gassed at $120^{\circ} \mathrm{C}$ for at least $6 \mathrm{~h}$. The Brunauer-Emmett-Teller (BET) specific surface areas were calculated using the adsorption data in the relative pressure $\left(P / P_{0}\right)$ range of $0.05-0.25$. Pore size distributions were calculated using the Barrett-Joyner-Halenda $(\mathrm{BJH})$ method based on the adsorption branch and Horvath-Kawazoe (HK) method. The total pore volumes were estimated from the amount adsorbed at a relative pressure $P / P_{0}$ of 0.99 . Transmission electron microscopy (TEM) was performed using a JEOL JEM-2000EX and a FEI Tecnai $\mathrm{G}^{2}$ Spirit at an acceleration voltage of $120 \mathrm{kV}$. Field-emission scanning electron microscopy (FESEM) was undertaken on a HITACHI S4800 microscope operating at an accelerating voltage of $1-30 \mathrm{kV}$. UV-vis diffuse reflectance spectra were recorded on a JASCO V-550 UV-vis spectrophotometer. The powder material was loaded into a quartz cell, and the spectra were collected in the range of $190-800 \mathrm{~nm}$ with $\mathrm{BaSO}_{4}$ as the reference. UV resonance Raman spectra were measured at room temperature with a Jobin-Yvon T64000 triple-stage spectrograph with a spectral resolution of $2 \mathrm{~cm}^{-1}$ [44]. The $290 \mathrm{~nm}$ line from a Coherent Innova 300 Fred laser was used as an excitation source. The power of the $290 \mathrm{~nm}$ line at samples was below $1.0 \mathrm{~mW}$. The Si content of the samples was determined by X-ray fluorescence spectrometer (XRF, Axios PW4400, Panalytical), and the Fe content was measured with Inductively Coupled Plasma Optical Emission Spectrometry (ICP-OES, IRIS Intrepid II XSP, Thermo Fisher) after the sample was dissolved in a mixture of $\mathrm{HF}$ and $\mathrm{HNO}_{3}$. The ammonia temperature-programmed desorption ( $\left.\mathrm{NH}_{3}-\mathrm{TPD}\right)$ was measured on a Micromeritics Autochem 2920 instrument. The catalyst $(0.15 \mathrm{~g})$ was charged in a U-shaped quartz cell and pretreated in $\mathrm{Ar}$ $\left(20 \mathrm{~mL} \mathrm{~min}^{-1}\right)$ at $500^{\circ} \mathrm{C}$ for $1 \mathrm{~h}$ (ramp rate $10^{\circ} \mathrm{C} \mathrm{min}^{-1}$ ), then cooled down to $100^{\circ} \mathrm{C}$ followed by changing the gas flow to a mixture of $10 \% \mathrm{NH}_{3}-90 \% \mathrm{Ar}\left(40 \mathrm{~mL} \mathrm{~min}^{-1}\right)$ for $2 \mathrm{~h}$. The sample was then purged with $\mathrm{Ar}\left(20 \mathrm{~mL} \mathrm{~min}^{-1}\right)$ at $100{ }^{\circ} \mathrm{C}$ for $2 \mathrm{~h}$ to remove free and weakly adsorbed ammonia. The $\mathrm{NH}_{3}$-TPD profile was obtained by rising the temperature up to $550^{\circ} \mathrm{C}\left(\right.$ ramp rate $10^{\circ} \mathrm{C} \mathrm{min}-1$ ), using a TCD detector. 


\section{Results and discussion}

\subsection{Synthesis}

As reported elsewhere, we have previously found that hollow silica nanospheres could be synthesized using the combination of F127-TMOS-TMB- $\mathrm{K}_{2} \mathrm{SO}_{4}$ under neutral conditions [43]. In order to incorporate the iron species in the siliceous hollow nanospheres, $\mathrm{Fe}(\mathrm{acac})_{3}$ was chosen as an iron source. The TEM images of NS- $n$ ( $n=0.8$ and 1.5) samples are displayed in Fig. 1. Mono-dispersed hollow nanospheres with shell thickness of $4.0 \mathrm{~nm}$ and core diameter of $12.0 \mathrm{~nm}$ could be clearly observed in the TEM image of NS0.8 sample. Similarly, NS-1.5 also has the hollow nanospherical morphology with the shell thickness of $4.4 \mathrm{~nm}$ and core diameter of $9.3 \mathrm{~nm}$. Increasing of the concentration of iron in the synthesis gel resulted in a slight decrease in the core diameter. From the SEM images (Fig. 2), it can be seen that both NS-0.8 and NS-1.5 samples have spherical morphology, but it is difficult to determine the accurate size of the spheres due to the resolution of the images. Thus the loading of iron provides a facile way of finely tuning the core diameter (size of interior void) of hollow nanospheres. Nitrogen sorption isotherms and BJH pore size distributions of Fe-NS- $n$ samples are depicted in Fig. 3A and B, respectively. Two capillary condensation steps (the first is from the interior core, and the second is from the interparticle void space) are present in all these isotherms, which is similar to the $\mathrm{N}_{2}$ sorption isotherms of previously reported hollow nanospheres $[20,43]$. The core diameters of the hollow nanospheres are in the range of 11.3 and $8.8 \mathrm{~nm}$ for Fe-NS-0.8 and Fe-NS-1.5, respectively (Table 1 ), which are consistent to those estimated from TEM. The BET surface area and pore volume of NS-1.5 is slightly higher than that of NS-0.8. The Fe content in NS-0.8 and NS-1.5 is of 0.51 and $0.85 \mathrm{wt} \%$, respectively (Table 1 ). In addition to the mesopores, the micropore size distribution from HK method indicates that NS-0.8 has micropores with diameter centered at ca. $0.5 \mathrm{~nm}$, as shown in Fig. 3C. The micropores are likely originated from the shell of the hollow nanospheres, which are randomly interconnected to reach the inner cavity $[20,43]$. The above characterizations suggest that the Fe-substituted hollow nanospheres have been successfully synthesized in the neutral reaction medium.

A comparative sample synthesized in a similar condition to NS0.8 but without using $\mathrm{K}_{2} \mathrm{SO}_{4}$ was obtained in very low yield. This indicates that $\mathrm{K}_{2} \mathrm{SO}_{4}$ plays a significant role in effective hydrolysis-polymerization of TMOS to form the spherical morphology in such an acid-free synthetic solution [16,45-47]. However, under strongly acidic conditions, it was reported that the F127-KCl-TMB system tends to form cage-like mesostructure $[42,46,47]$. Under neutral buffer solution $\left(\mathrm{NaH}_{2} \mathrm{PO}_{4}-\mathrm{Na}_{2} \mathrm{HPO}_{4}, \mathrm{pH} \approx 7.0\right)$, the formation of nanospheres was investigated in details [48], where inorganic salt from buffer solution may play a similar role to $\mathrm{K}_{2} \mathrm{SO}_{4}$ in the present work. Given that the surfactant F127 may exist as individual micelles in the current system, the hollow nanospheres could be formed by condensation of hydrolyzed TMOS species around these single F127 micelles $[27,48]$. In this case, $\mathrm{Fe}(\mathrm{acac})_{3}$ is well dissolved in TMOS but not in water, so that Fe might be incorporated into the silica framework during the hydrolysis and condensation process of TMOS for the formation of $\mathrm{Si}-\mathrm{O}-\mathrm{Si}$ species.

The $\mathrm{NO}_{3}-\mathrm{NS}-n(n=0.8,1.5$, and 2.3$)$ samples were synthesized under similar conditions to NS- $n$ samples but using $\mathrm{Fe}\left(\mathrm{NO}_{3}\right)_{3}$ as iron source and lower $\mathrm{H}_{2} \mathrm{O} / \mathrm{F} 127$ ratio (the $\mathrm{H}_{2} \mathrm{O} / \mathrm{F} 127$ molar ratio for $\mathrm{NO}_{3}$-NS- $n$ and NS- $n$ is 28,000 and 42,000 , respectively). The XRD patterns of $\mathrm{NO}_{3}-\mathrm{NS}-n(n=0.8,1.5$, and 2.3) samples show one prominent peak in the low-angle range, indicating the formation of mesoporous materials (Fig. 4). $\mathrm{NO}_{3}$-NS-2.3 has less ordering compared with $\mathrm{NO}_{3}-\mathrm{NS}-0.8$ and $\mathrm{NO}_{3}-\mathrm{NS}-1.5$. The TEM technique was used for further characterization of the structure of $\mathrm{NO}_{3}-\mathrm{NS}-n$ samples $\left(n=0.8,1.5\right.$, and 2.3) (Fig. 5). The TEM image of $\mathrm{NO}_{3}-\mathrm{NS}-0.8$ clearly shows that this sample has typical FDU-12 cage-like mesostructures. The ordered lattice array over large domains under the TEM observations suggests that the sample has a uniform, cubic mesostructure (Fm-3m) without intergrowth [46,47]. The diameter of the cages may be directly measured from the thin edge of the particle in Fig. 5 a to be about $17.1 \mathrm{~nm}$, in good accordance with the $\mathrm{N}_{2}$ sorption results (see below). Moreover, large pores formed can be regarded as the linear combination of many spherical cages for $\mathrm{NO}_{3}$-NS-0.8. Increasing $\mathrm{Fe} / \mathrm{Si}$ molar ratio to 0.015 leads to the aggregated hollow nanospheres with particle size of $25.2 \mathrm{~nm}$ and shell thickness of $5.1 \mathrm{~nm}$, as can be clearly observed in the TEM image of $\mathrm{NO}_{3}$-NS-1.5 (Fig. 5b). When Fe/Si molar ratio reaches to 0.023, the co-existence of hollow nanospheres with particle size of $25.0 \mathrm{~nm}$ and shell thickness of $6.0 \mathrm{~nm}$ and broken hollow nanspheres was observed (Fig. 5c). The SEM images of $\mathrm{NO}_{3}-\mathrm{NS}-n$ samples are shown in Fig. 6. $\mathrm{NO}_{3}-\mathrm{NS}-0.8$ is composed of microspheres with particle size of $1-2 \mu \mathrm{m}$. The microspheres which are composed of nanospheres were found in the SEM image of $\mathrm{NO}_{3}$-NS-1.5 (Fig. 6b). The nanospheres could be clearly observed in the SEM images of $\mathrm{NO}_{3}$-NS-2.3 sample. The above results further confirm that $\mathrm{NO}_{3}-\mathrm{NS}-n(n=1.5$ and 2.3 ) samples have nanospherical morphology.

The nitrogen sorption isotherms and $\mathrm{BJH}$ pore size distributions of $\mathrm{NO}_{3}$-NS- $n(n=0.8,1.5$, and 2.3$)$ are displayed in Fig. 7 . The textural parameters are compiled in Table $1 . \mathrm{NO}_{3}-\mathrm{NS}-0.8$ is of type IV isotherms with a steep $\mathrm{H} 2$ hysteresis loop at the relative pressure of $P / P_{0}=0.45-0.90$, characteristic of mesoporous materials with a cage-like pore structure [46]. The $\mathrm{N}_{2}$ adsorption isotherm of $\mathrm{NO}_{3}$-NS-1.5 is similar to that of $\mathrm{NO}_{3}-\mathrm{NS}-0.8$, but the two-step desorption isotherm were observed in the former sample. The desorption step at $P / P_{0}$ higher than 0.70 may be from the closely connected hollow nanospheres. The isotherms of $\mathrm{NO}_{3}-\mathrm{NS}-2.3$ show very clear two-step capillary condensation, which is very similar to those of hollow nanospheres as shown in Fig. 3. The $\mathrm{N}_{2}$ sorption isotherms of $\mathrm{NO}_{3}-\mathrm{NS}-1.5$ are different from that of the highly

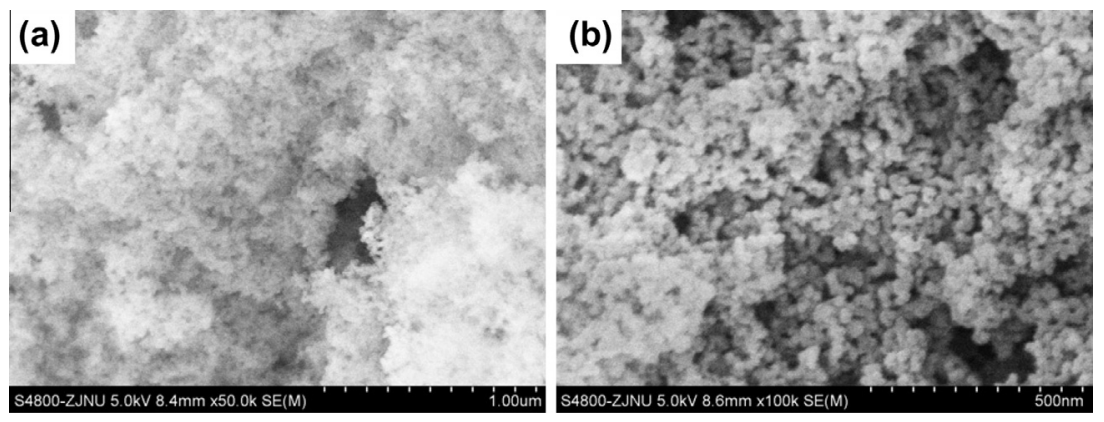

Fig. 2. SEM images of Fe-substituted hollow nanospheres: (a) NS-0.8 and (b) NS-1.5. 

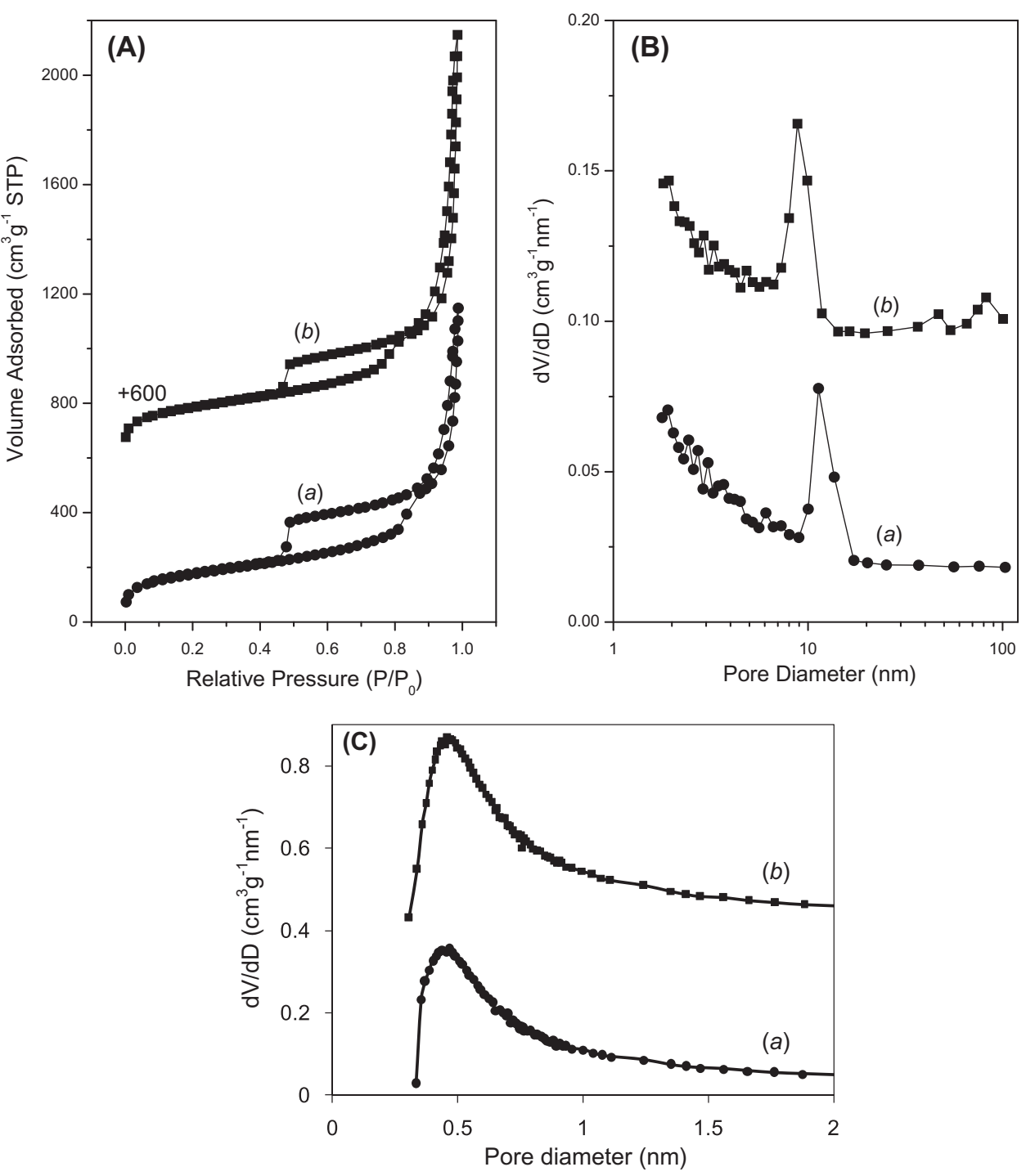

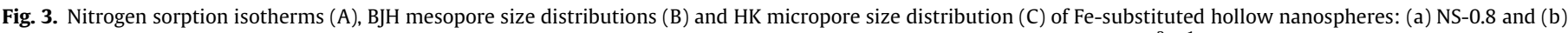
NS-1.5 (+600 in the left panel means that the nitrogen isotherms of (b) are shifted manually upwards along $y$-axis by $600 \mathrm{~cm}^{3} \mathrm{~g}^{-1} \mathrm{STP}_{\text {). }}$

Table 1

Structural parameters of Fe-containing mesoporous silicas.

\begin{tabular}{|c|c|c|c|c|c|c|}
\hline \multirow[t]{2}{*}{ Material } & \multicolumn{2}{|l|}{$\mathrm{pH}$} & \multirow[t]{2}{*}{ Fe content (wt. \%) } & \multirow[t]{2}{*}{$S_{\mathrm{BET}}{ }^{\mathrm{a}}\left(\mathrm{m}^{2} \mathrm{~g}^{-1}\right)$} & \multirow[t]{2}{*}{$V_{\mathrm{t}}^{\mathrm{b}}\left(\mathrm{cm}^{3} \mathrm{~g}^{-1}\right)$} & \multirow[t]{2}{*}{$D_{\mathrm{BJH}}{ }^{\mathrm{C}}(\mathrm{nm})$} \\
\hline & Initial & Final & & & & \\
\hline NS-0.8 & 5.34 & 5.00 & 0.51 & 620 & 1.78 & 11.3 \\
\hline NS-1.5 & 5.41 & 4.90 & 0.85 & 655 & 2.39 & 8.8 \\
\hline NO3-NS-0.8 & 3.42 & 3.39 & 0.28 & 715 & 0.76 & 15.6 \\
\hline NO3-NS-1.5 & 3.28 & 3.28 & 0.56 & 745 & 0.97 & 18.8 \\
\hline NO3-NS-2.3 & 3.16 & 3.01 & 1.81 & 948 & 1.36 & 15.3 \\
\hline
\end{tabular}

${ }^{\text {a }} S_{\mathrm{BET}}$ is the BET specific surface area.

b $V_{\mathrm{t}}$ is the total pore volume determined at the relative pressure of 0.98 .

c $D_{\mathrm{BJH}}$ is $\mathrm{BJH}$ pore diameter calculated by the adsorption branches of the nitrogen sorption isotherms.

dispersed hollow nanospheres, which suggests that the hollow nanospheres in the sample are combined with each other more tightly. The nitrogen sorption isotherms clearly show the evolution from FDU-12 mesostructure to hollow nanospheres as the iron content in the initial mixture increases, consistent with TEM and SEM characterization.

Generally, the $\mathrm{pH}$ value of synthesis gel plays important role in the synthesis of porous silicas. We have measured the $\mathrm{pH}$ value of the synthesis gels before transferring into the autoclave (initial $\mathrm{pH}$ ) and the final $\mathrm{pH}$ value of reaction system (final $\mathrm{pH}$ ), as shown in Table 1. For the hollow nanospheres NS-0.8 and NS-1.5, the initial $\mathrm{pH}$ and final $\mathrm{pH}$ are quite close and weak acidic (around 5), because the synthesis system does not introduce external acid sources and the acidity does not change dramatically during the hydrothermal process. We also reported previously the synthesis of pure siliceous hollow nanosphere in the F127-TMOS-TMB- $\mathrm{K}_{2} \mathrm{SO}_{4}$ system, and found that the $\mathrm{pH}$ value does not apparently affect the formation of hollow nanospheres when changing the $\mathrm{pH}$ from 6.33 to 


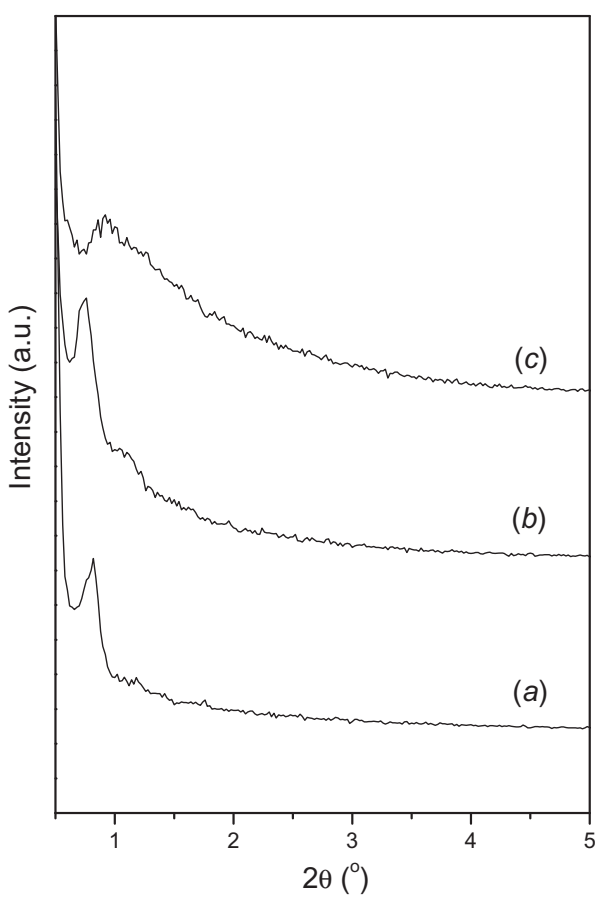

Fig. 4. XRD patterns of $\mathrm{NO}_{3}-\mathrm{NS}-n$ samples: (a) $\mathrm{NO}_{3}-\mathrm{NS}-0.8$, (b) $\mathrm{NO}_{3}-\mathrm{NS}-1.5$, and (c) $\mathrm{NO}_{3}$-NS-2.3.

3.80 with $\mathrm{H}_{2} \mathrm{SO}_{4}$ [43]. Different from $\mathrm{Fe}(\mathrm{acac})_{3}$ insoluble in water, $\mathrm{Fe}\left(\mathrm{NO}_{3}\right)_{3}$ can generate higher acidity when hydrolyzed in water medium, so the initial $\mathrm{pH}$ and final $\mathrm{pH}$ are both acidic in the range of 3-4. This is also similar to the case of introducing divalent salts, i.e., $\mathrm{CuSO}_{4}$ or $\mathrm{MgSO}_{4}$ [43]. This acidity may strengthen the interaction between silica species and micelles [46,49], and thereby facilitate the formation of FDU-12 type mesostructure of $\mathrm{NO}_{3}-\mathrm{NS}-0.8$. Under neutral conditions, the monodisperse mesoporous silica nanospheres were recently synthesized successfully in a large scale [50]. Despite the silica nanospheres are not hollow, a three-step formation mechanism is well proposed and interpreted, in which the self-assembly may take place between polymerizing silicate oligomers and individual surfactant micelles [50].

On the other hand, the salt effect was also highlighted [43], that is, in the F127-TMOS-TMB system, univalent salts (such as $\mathrm{K}_{2} \mathrm{SO}_{4}$ and $\mathrm{Na}_{2} \mathrm{SO}_{4}$ ) facilitate the formation of hollow nanospheres, divalent salts (such as $\mathrm{CuSO}_{4}$ and $\mathrm{MgSO}_{4}$ ) help to produce FDU-12 structures. We here further extend the salt effect to trivalent salt (such as $\left.\mathrm{Fe}\left(\mathrm{NO}_{3}\right)_{3}\right)$. A certain amount of trivalent salt produces ordered FDU-12 structure in addition to the decrease of $\mathrm{pH}$ value, and higher concentration of trivalent Fe salt will lead to less ordered FDU-12 ( $\left.\mathrm{NO}_{3}-\mathrm{NS}-1.5\right)$, in accrodance with the case of divalent salt $\mathrm{CuSO}_{4}$ [43]. Even higher concentration of $\mathrm{Fe}\left(\mathrm{NO}_{3}\right)_{3}$ forms less ordered hollow nanospheres $\left(\mathrm{NO}_{3}-\mathrm{NS}-2.3\right)$, which is seemingly evolved from the disassociated cages of FDU-12. When the concentration of $\mathrm{Fe}\left(\mathrm{NO}_{3}\right)_{3}$ increases, however, the fast hydrolysis and condensation rate of siliceous species at lower $\mathrm{pH}$ value may disturb the assembly process of ordered mesoporous structure and the hydrolyzed silicon species tend to assembly around the surfactant micelles to form the hollow nanospheres. The structural evolution again indicates the facile conversion between cage-like and nanospherical structures $[19,43]$. This would be helpful to further understand the formation mechanism of the two kinds of mesoporous silicas.
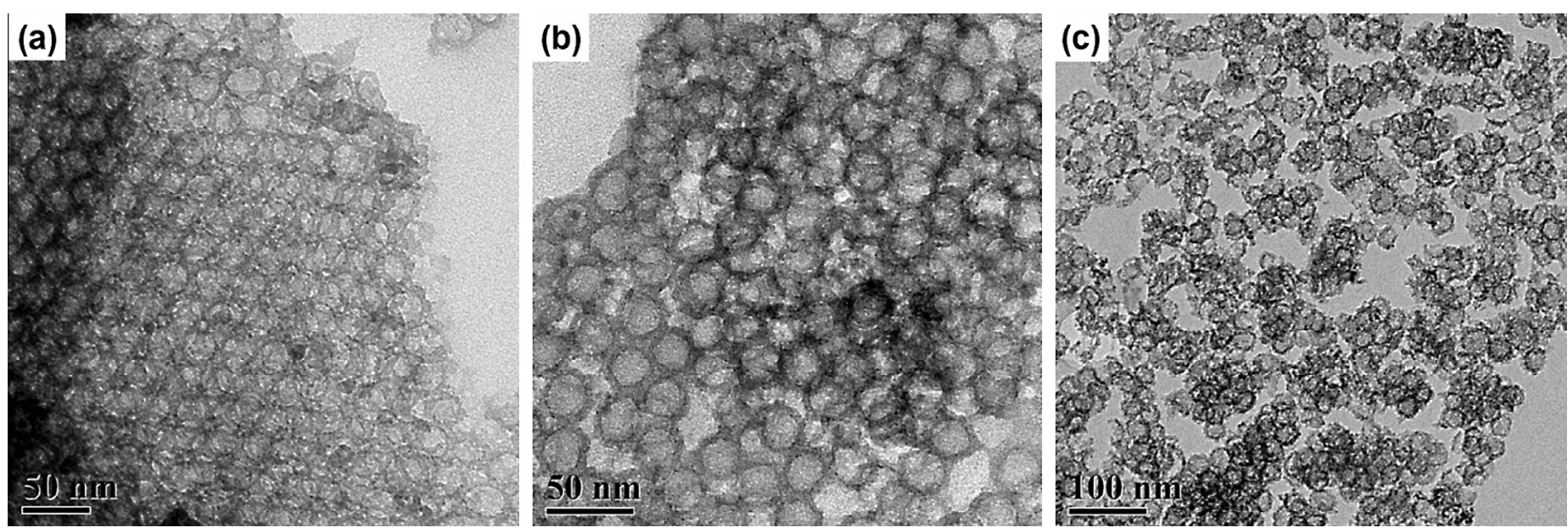

Fig. 5. TEM images of $\mathrm{NO}_{3}-\mathrm{NS}-n$ samples: (a) $\mathrm{NO}_{3}-\mathrm{NS}-0.8$, (b) $\mathrm{NO}_{3}-\mathrm{NS}-1.5$, and (c) $\mathrm{NO}_{3}-\mathrm{NS}-2.3$.
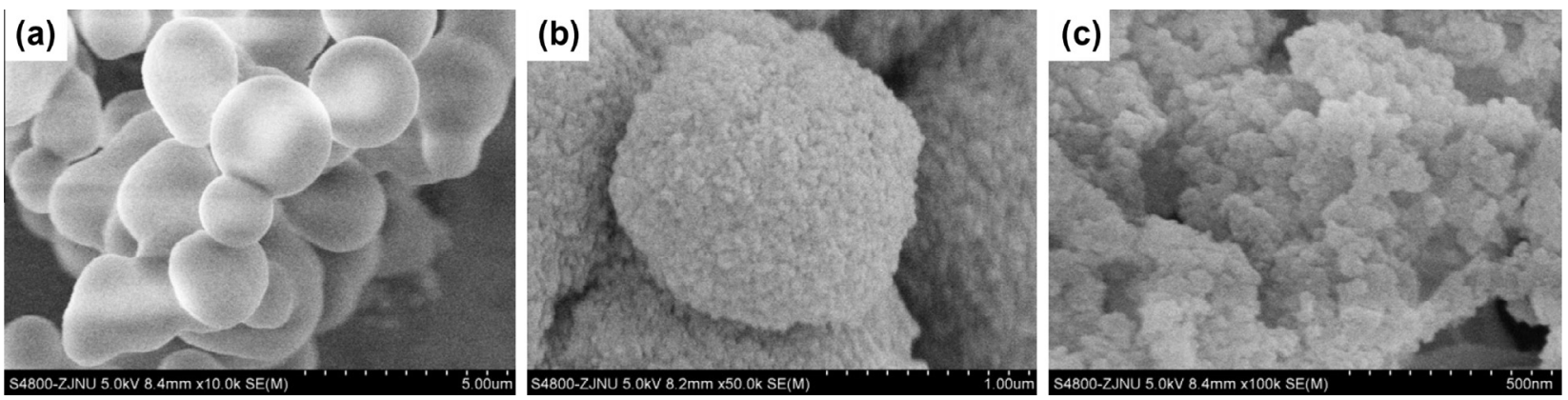

Fig. 6. SEM images of $\mathrm{NO}_{3}-\mathrm{NS}-n$ samples: (a) $\mathrm{NO}_{3}-\mathrm{NS}-0.8$, (b) $\mathrm{NO}_{3}-\mathrm{NS}-1.5$, and (c) $\mathrm{NO}_{3}-\mathrm{NS}-2.3$. 

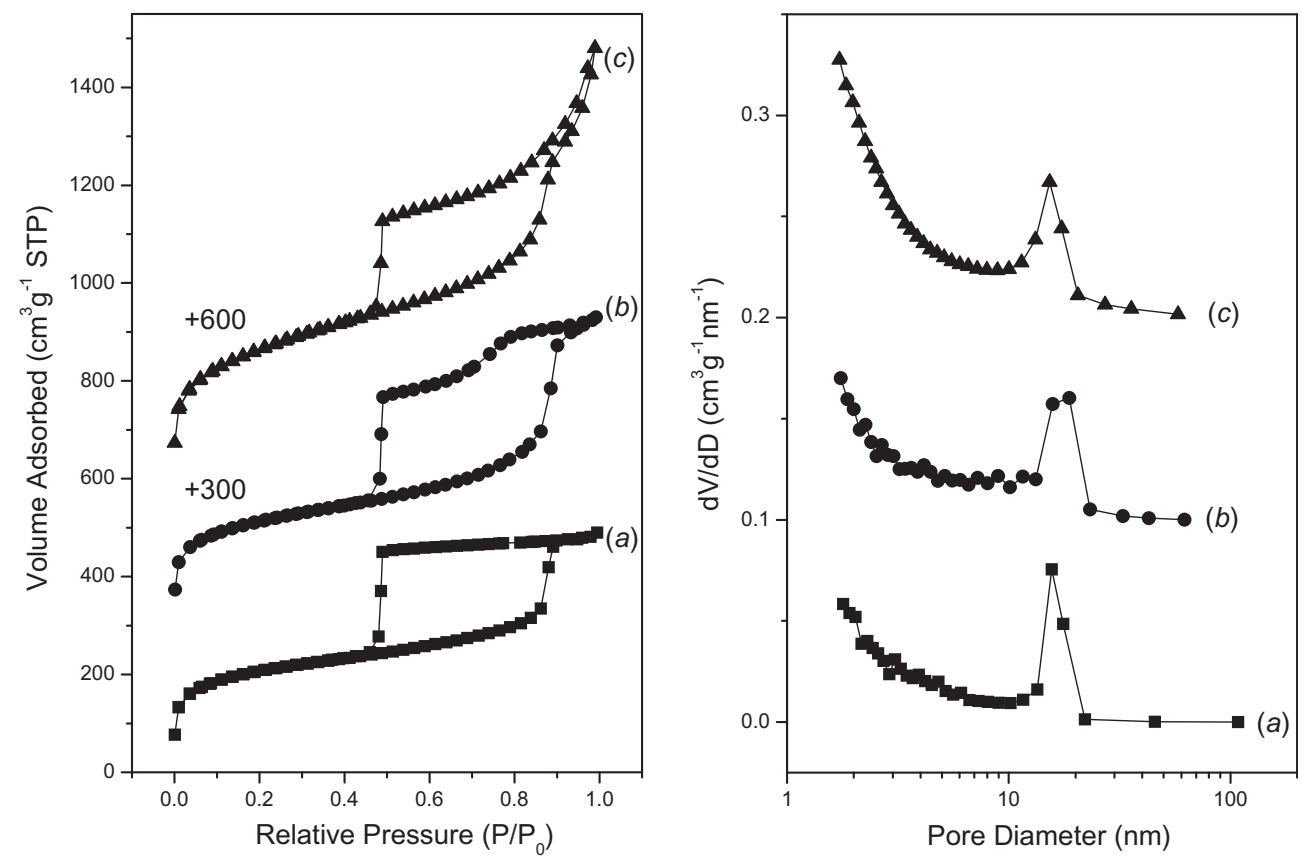

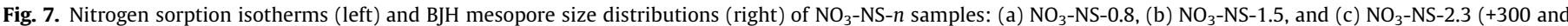

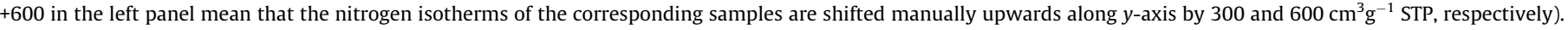

To study the role of TMB in the formation of hollow nanospheres and cage-like mesostructures, $\mathrm{NS}^{*}-0.8$ and $\mathrm{NO}_{3}-\mathrm{NS}^{*}-0.8$ were synthesized without TMB, compared with their counterparts, NS-0.8 and $\mathrm{NO}_{3}$-NS-0.8, respectively. The TEM images of the two samples are shown in Fig. 8. Clearly, NS*-0.8 show hollow structure but the nanospheres are not separated well. This is in accordance with our previous study in the F127-TMB system for the synthesis of hollow nanospheres [42], where the aggregated hollow organosilica nanospheres are formed in the absence of TMB. This may imply that TMB may act as a swelling agent to penetrate into the core of micelles formed by $\mathrm{EO}_{106} \mathrm{PO}_{70} \mathrm{EO}_{106}$ (F127) copolymers. Compared with $\mathrm{NO}_{3}-\mathrm{NS}-0.8$, ordered cage-like mesostructure cannot be seen in the sample $\mathrm{NO}_{3}-\mathrm{NS}^{*}-0.8$, but worm-like structures are formed instead. These two samples strongly demonstrate that TMB plays an important role in the synthesis of hollow nanospheres and cage-like FDU-12 in the present synthesis system.

Efforts to induce the phase transformation for ordered mesostructure to hollow nanospheres were made previously by varying synthetic parameters, for example, by variation of valence state inorganic salt addictive [43] and synthesis temperature [19]. Herein, for the first time, we realized the transformation between FDU12 structure and hollow nanospheres by simply using different iron salts.

\subsection{Characterization of iron species by UV-vis spectroscopy}

The elemental analysis results of NS- $n$ and $\mathrm{NO}_{3}-\mathrm{NS}-n$ samples are compiled in Table 1. As expected, more iron ions are incorporated in the samples with increased $\mathrm{Fe} / \mathrm{Si}$ ratio of the synthesis gel. Compared with $\mathrm{NO}_{3}$-NS- $n$ samples, NS- $n$ samples have more incorporated iron. This is probably due to the neutral conditions in the synthesis of NS- $n$ samples using $\mathrm{Fe}(\mathrm{acac})_{3}$ as iron source.

UV-vis spectroscopy may be used to identify different iron species in porous materials [51-53]. UV-vis spectra of NS- $n$ and $\mathrm{NO}_{3}$-NS- $n$ are displayed in Fig. 9. NS-0.8 displays peaks centered at ca. 220 and $250 \mathrm{~nm}$, which can be assigned to isolated tetrahedrally-coordinated framework sites [54]. NS-1.5 only shows a weak shoulder at $350 \mathrm{~nm}$, but tailing above $400 \mathrm{~nm}$ suggests the
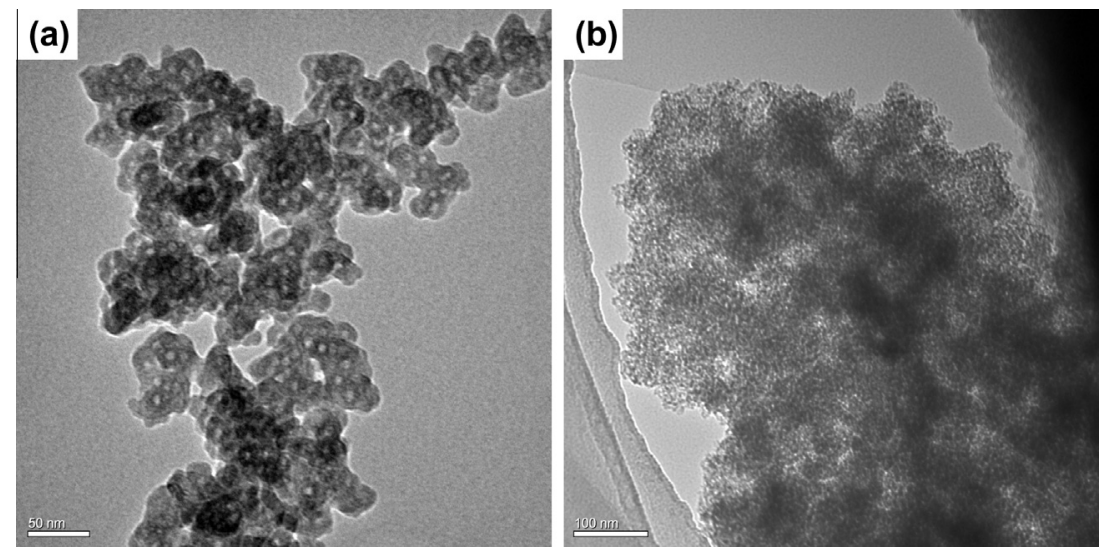

Fig. 8. TEM images of samples synthesized without TMB: (a) NS*-0.8 and (b) $\mathrm{NO}_{3}-\mathrm{NS}^{*} 0.8$. 

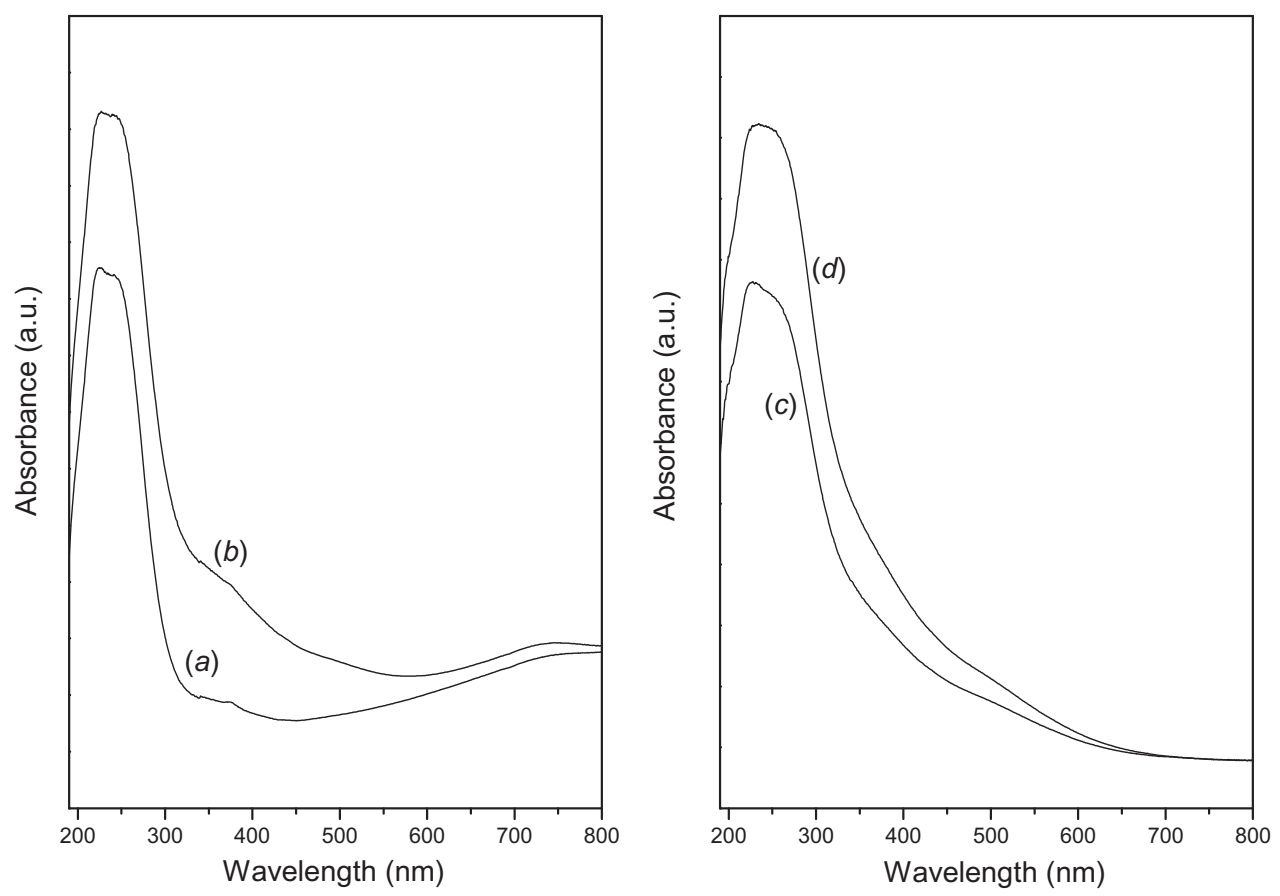

Fig. 9. UV-vis spectra of Fe-containing mesoporous silicas: (a) NS-0.8, (b) NS-1.5, (c) $\mathrm{NO}_{3}-\mathrm{NS}^{-0.8}$, and (d) $\mathrm{NO}_{3}-\mathrm{NS}-1.5$.

existence of a small quantity of aggregates [55,56]. This implies that not all the iron species in the initial mixture could be tetrahedrally-coordinated in the mesoporous framework when the iron content in the initial mixture is too high.

$\mathrm{NO}_{3}$-NS- $n$ samples show quite similar UV-vis spectra (Fig. 9), where the two distinct peaks centered at ca. 220 and $250 \mathrm{~nm}$ can be assigned to isolated tetrahedrally coordinated iron ions. The peaks in the UV-vis spectra of $\mathrm{NO}_{3}-\mathrm{NS}-n$ samples are wider than that of NS- $n$ samples. This shows that $\mathrm{Fe}(\mathrm{acac})_{3}$ as iron source is more favorable for the formation of tetrahedral coordination of iron in the framework.

\subsection{Characterization of iron species by UV-Raman spectroscopy}

UV resonance Raman spectroscopy is a powerful technique to characterize transition metals in the framework of zeolites or mesoporous silicas [44,57]. Using UV excitation, low fluorescence interference and strong resonance Raman enhancement make it possible for the sensitive detection of highly-isolated Ti or Fe species in mesoporous silicas or microporous zeolites [58,59]. A $290 \mathrm{~nm}$ laser line was employed as the excitation line, which is close in energy to the charge transfer band as indicated in the UV-vis spectra of NS- $n$ and $\mathrm{NO}_{3}$-NS- $n$ samples. The UV Raman spectra of NS- $n$ and $\mathrm{NO}_{3}$-NS- $n$ samples (Fig. 10) primarily exhibit bands at $510,978,1090$, and $1150 \mathrm{~cm}^{-1}$. The bands at 510 and $1090 \mathrm{~cm}^{-1}$ are attributed to the symmetric and asymmetric stretching vibrations of the framework $\mathrm{Fe}-\mathrm{O}-\mathrm{Si}$ species, respectively, due to the resonance Raman effect $[60,61]$. Weak bands at $1150 \mathrm{~cm}^{-1}$ are attributed to the $\mathrm{Fe}-\mathrm{O}$ stretching vibration couple to stretching of four neighboring framework $\mathrm{Si}-\mathrm{O}-\mathrm{Si}$ bonds. The band at $978 \mathrm{~cm}^{-1}$ is associated with the $\mathrm{Si}-\mathrm{O}-\mathrm{Si}$ bond near the isolated iron species or the surface silanol group [14,49]. The UV-Raman spectra of $\mathrm{NO}_{3}$-NS-n samples are quite similar, also exhibiting some main bands at $510,978,1090$, and $1150 \mathrm{~cm}^{-1}$, indicative of isolated iron species are present in these samples. The spectroscopic results (UV-vis and UV-Raman spectra) strongly suggest that highly isolated Fe species are present in all these hollow nanospheres and FDU-12 materials.

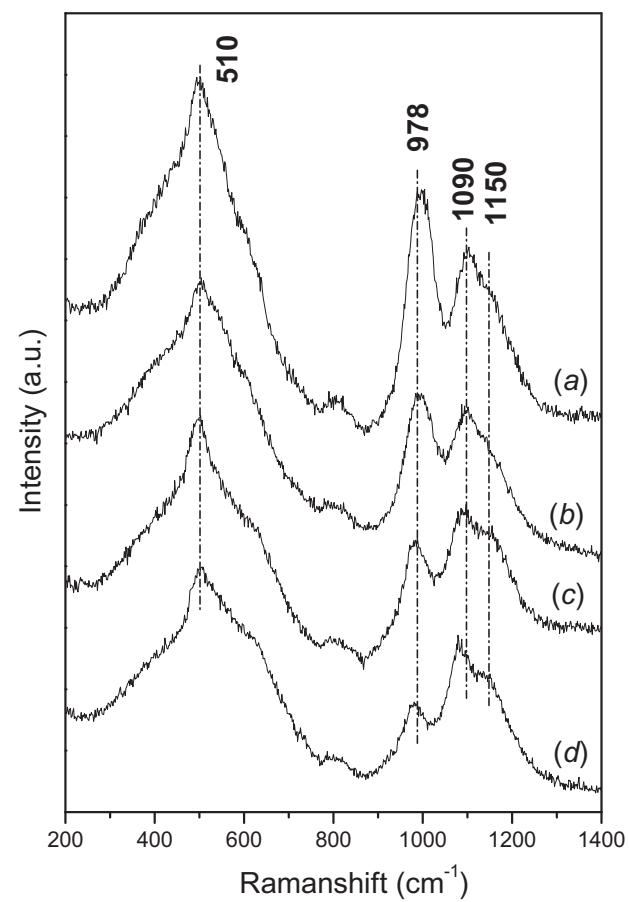

Fig. 10. UV-Raman spectra of Fe-containing mesoporous silicas: (a) NS-0.8, (b) NS1.5 , (c) $\mathrm{NO}_{3}-\mathrm{NS}-0.8$, and (d) $\mathrm{NO}_{3}-\mathrm{NS}-1.5$.

\subsection{Characterization of acidity by $\mathrm{NH}_{3}-\mathrm{TPD}$}

The $\mathrm{NH}_{3}$-TPD is generally used to characterize the acidity of zeolites and mesoporous silicas [62,63]. As shown in Fig. 11, for $\mathrm{NS}-0.8$, there is only one ammonia desorption peak at ca. $170^{\circ} \mathrm{C}$, which can be attributed to ammonia adsorbed on weak acid sites. Compared with the strong acid sites on zeolites [62], the Fe-containing hollow nanospheres have relatively weak acidity, which may be favorable to the catalytic reactions requiring weak acidity. 


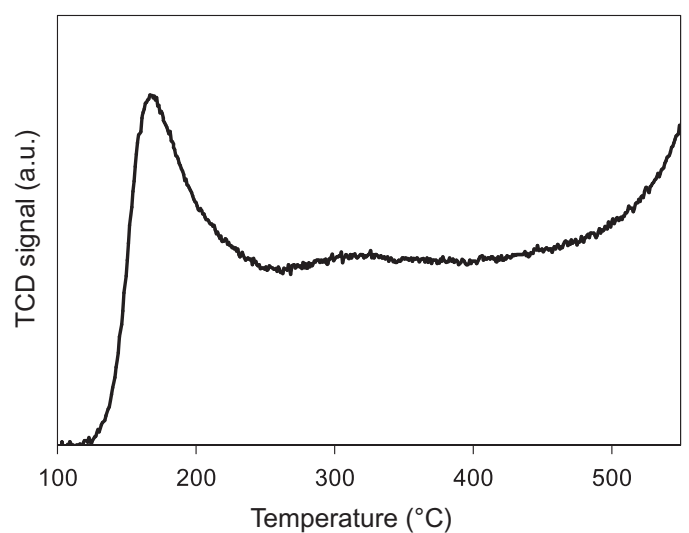

Fig. 11. $\mathrm{NH}_{3}-\mathrm{TPD}$ spectrum of $\mathrm{NS}-0.8$.

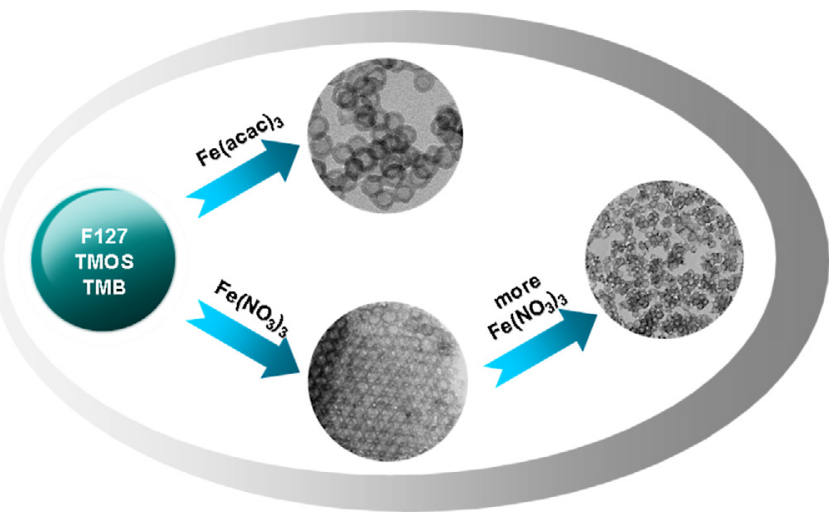

Scheme 1. Schematic illustration of the acid-free procedures for the synthesis of Fe-substituted mesoporous silicas.

From all the results and discussion above, the transformation has been realized between hollow nanospheres and cubic cage-like pore structure, by varying iron salts (Scheme 1 ). When the iron loading is relatively low, highly isolated iron centers are predominant in these materials. These isolated iron species are supposed to be responsible for the catalytic activity in certain reactions, especially oxidative reactions $[52,61]$.

\section{Conclusions}

In summary, a facile synthesis procedure has been developed to prepare Fe-substituted hollow nanospheres and Fe-FDU-12 with well-isolated iron sites in the absence of mineral acid. The evolution between hollow nanospheres and cage-like structures was achieved by the variation of iron precursors. This is an environmentally friendly methodology of nanostructure synthesis. This acid-free route may potentially be viable with other acid- and base-sensitive synthesis and encapsulation procedures.

\section{Acknowledgments}

The authors are grateful to Prof. Can Li for UV-Raman characterization from Dalian Institute of Chemical Physics, Chinese Academy of Sciences and Prof. Mengfei Luo and Ms. Panjing Hu for FESEM images from Zhejiang Normal University. This work was financially supported by the National Science Foundation of China (220923001, 21232008) and Doctoral Fund of Shandong Province (BS2013CL029).

\section{Reference}

[1] Y. Wan, D.Y. Zhao, Chem. Rev. 107 (2007) 2821-2860.

[2] M.E. Davis, Nature 417 (2002) 813-821.

[3] Q.H. Yang, D.F. Han, H.Q. Yang, C. Li, Chem. Asian J. 3 (2008) 1214-1229.

[4] J. Fan, S.W. Boettcher, C.K. Tsung, Q. Shi, M. Schierhorn, G.D. Stucky, Chem. Mater. 20 (2008) 909-921.

[5] A. Corma, Chem. Rev. 97 (1997) 2373-2419.

[6] D.T. On, D. Desplantier-Giscard, C. Danumah, S. Kaliaguine, Appl. Catal. A 222 (2001) 299-357.

[7] G.V. Shanbhag, M. Choi, J. Kim, R. Ryoo, J. Catal. 264 (2009) 88-92.

[8] Y. Han, X.J. Meng, H.B. Guan, Y. Yu, L. Zhao, X.Z. Xu, X.Y. Yang, S. Wu, N. Li, F.S. Xiao, Micropor. Mesopor. Mater. 57 (2003) 191-198.

[9] A. Tuel, I. Arcon, J.M.M. Millet, J. Chem. Soc. Faraday Trans. 94 (1998) 35013510.

[10] Z.Y. Yuan, S.Q. Liu, T.H. Chen, J.Z. Wang, H.X. Li, J. Chem. Soc. Chem. Commun. (1995) 973-974.

[11] W. Schmidt, ChemCatChem 1 (2009) 53-67.

[12] X.J. Meng, F. Nawaz, F.S. Xiao, Nano Today 4 (2009) 292-301.

[13] Y. Wan, Y.F. Shi, D.Y. Zhao, Chem. Commun. (2007) 897-926.

[14] H.C. Xin, J. Liu, F.T. Fan, Z.C. Feng, G.Q. Jia, Q.H. Yang, C. Li, Micropor. Mesopor. Mater. 113 (2008) 231-239.

[15] J.T. Tang, J. Liu, J. Yang, Z.C. Feng, F.T. Fan, Q.H. Yang, J. Colloid Interface Sci. 335 (2009) 203-209.

[16] H.C. Xin, J.T. Tang, F.T. Fan, Q.H. Yang, C. Li, J. Inorg. Mater. 25 (2010) 107-112.

[17] J.T. Tang, H.C. Xin, W.G. Su, J. Liu, C. Li, Q.H. Yang, J. Catal. 31 (2010) 386-393.

[18] J.M. Thomas, R. Raja, D.W. Lewis, Angew. Chem. Int. Ed. 44 (2005) 6456-6482.

[19] J.W. Tang, X.F. Zhou, D.Y. Zhao, G.Q. Lu, J. Zou, C.Z. Yu, J. Am. Chem. Soc. 129 (2007) 9044-9048.

[20] J. Liu, Q.H. Yang, L. Zhang, H.Q. Yang, J.S. Gao, C. Li, Chem. Mater. 20 (2008) 4268-4275.

[21] A.F. Zhang, Y.C. Zhang, N. Xing, K.K. Hou, X.W. Guo, Chem. Mater. 21 (2009) 4122-4126.

[22] X. Li, Y. Yang, Q. Yang, J. Mater. Chem. A 1 (2013) 1525-1535.

[23] J.S. Gao, J. Liu, S.Y. Bai, P.Y. Wang, H. Zhong, Q.H. Yang, C. Li, J. Mater. Chem. 19 (2009) 8580-8588.

[24] Y.S. Lin, S.H. Wu, C.T. Tseng, Y. Hung, C. Chang, C.Y. Mou, Chem. Commun. (2009) 3542-3544.

[25] Q. Zhang, W.S. Wang, J. Goebl, Y.D. Yin, Nano Today 4 (2009) 494-507.

[26] J. Liu, F. Liu, K. Gao, J.S. Wu, D.F. Xue, J. Mater. Chem. 19 (2009) 6073-6084.

[27] J. Zhu, J.W. Tang, L.Z. Zhao, X.F. Zhou, Y.H. Wang, C.Z. Yu, Small 6 (2010) 276 282.

[28] S.-H. Wu, Y. Hung, C.-Y. Mou, Chem. Mater. 25 (2013) 352-364.

[29] Y. Yang, J. Liu, S. Bai, X. Li, Q. Yang, Chem. Asian J. 8 (2013) 582-587.

[30] P. Wang, S. Bai, J. Zhao, P. Su, Q. Yang, C. Li, ChemSusChem 5 (2012) 23902396.

[31] Y. Yang, X. Liu, X. Li, J. Zhao, S. Bai, J. Liu, Q. Yang, Angew. Chem. Int. Ed. 51 (2012) 9164-9168.

[32] X. Li, X. Liu, Y. Ma, M. Li, J. Zhao, H. Xin, L. Zhang, Y. Yang, C. Li, Q. Yang, Adv. Mater. 24 (2012) 1424-1428.

[33] S. Bai, J. Liu, J. Gao, Q. Yang, C. Li, Micropor. Mesopor. Mater. 151 (2012) 474480.

[34] Y. Yang, J. Liu, X. Li, X. Liu, Q. Yang, Chem. Mater. 23 (2011) 3676-3684.

[35] J. Gao, J. Liu, J. Tang, D. Jiang, B. Li, Q. Yang, Chem. Eur. J. 16 (2010) 7852-7858.

[36] F.Q. Tang, L.L. Li, D. Chen, Adv. Mater. 24 (2012) 1504-1534.

[37] J. Liu, S.Z. Qiao, J.S. Chen, X.W. Lou, X.R. Xing, G.Q. Lu, Chem. Commun. 47 (2011) 12578-12591.

[38] M. Sasidharan, H. Zenibana, M. Nandi, A. Bhaumik, K. Nakashima, Dalton Trans. 42 (2013) 13381-13389.

[39] F. Caruso, R.A. Caruso, H. Mohwald, Science 282 (1998) 1111-1114.

[40] S.K. Das, M.K. Bhunia, D. Chakraborty, A.R. Khuda-Bukhsh, A. Bhaumik, Chem. Commun. 48 (2012) 2891-2893.

[41] J. Liu, S.B. Hartono, Y.G. Jin, Z. Li, G.Q. Lu, S.Z. Qiao, J. Mater. Chem. 20 (2010) 4595-4601.

[42] J. Liu, S.Y. Bai, H. Zhong, C. Li, Q.H. Yang, J. Phys. Chem. C 114 (2010) 953-961.

[43] J.T. Tang, J. Liu, P.Y. Wang, H. Zhong, Q.H. Yang, Micropor. Mesopor. Mater. 127 (2010) 119-125.

[44] C. Li, J. Catal. 216 (2003) 203-212.

[45] L. Zhang, Q.H. Yang, W.H. Zhang, Y. Li, J. Yang, D.M. Jiang, G.R. Zhu, C. Li, J. Mater. Chem. 15 (2005) 2562-2568.

[46] J. Fan, C.Z. Yu, T. Gao, J. Lei, B.Z. Tian, L.M. Wang, Q. Luo, B. Tu, W.Z. Zhou, D.Y. Zhao, Angew. Chem. Int. Ed. 42 (2003) 3146-3150.

[47] J. Fan, C.Z. Yu, J. Lei, Q. Zhang, T.C. Li, B. Tu, W.Z. Zhou, D.Y. Zhao, J. Am. Chem. Soc. 127 (2005) 10794-10795.

[48] J. Liu, F. Fan, Z. Feng, L. Zhang, S. Bai, Q. Yang, C. Li, J. Phys. Chem. C 112 (2008) $16445-16451$.

[49] Y. Li, Z.C. Feng, H.C. Xin, F.T. Fan, J. Zhang, P. Magusin, E.J.M. Hensen, R.A. van Santen, Q.H. Yang, C. Li, J. Phys. Chem. B 110 (2006) 26114-26121.

[50] K. Zhang, L.-L. Xu, J.-G. Jiang, N. Calin, K.-F. Lam, S.-J. Zhang, H.-H. Wu, G.D. Wu, B. Albela, L. Bonneviot, P. Wu, J. Am. Chem. Soc. 135 (2013) 24272430.

[51] J.L. Long, X.X. Wang, Z.X. Ding, Z.Z. Zhang, H.X. Lin, W.X. Dai, X.Z. Fu, J. Catal. 264 (2009) 163-174.

[52] Y. Wang, W. Yang, L.J. Yang, X.X. Wang, Q.H. Zhang, Catal. Today 117 (2006) $156-162$. 
[53] C. Nozaki, C.G. Lugmair, A.T. Bell, T.D. Tilley, J. Am. Chem. Soc. 124 (2002) $13194-13203$.

[54] E.J.M. Hensen, Q. Zhu, R.A.J. Janssen, P. Magusin, P.J. Kooyman, R.A. van Santen, J. Catal. 233 (2005) 123-135.

[55] A.J.J. Koekkoek, W. Kim, V. Degirmenci, H. Xin, R. Ryoo, E.J.M. Hensen, J. Catal. 299 (2013) 81-89.

[56] A.J.J. Koekkoek, H. Xin, Q. Yang, C. Li, E.J.M. Hensen, Micropor. Mesopor. Mater. 145 (2011) 172-181.

[57] F.T. Fan, Z.C. Feng, C. Li, Acc. Chem. Res. 43 (2010) 378-387.

[58] H.C. Xin, J. Zhao, S.T. Xu, J.P. Li, W.P. Zhang, X.W. Guo, E.J.M. Hensen, Q.H. Yang, C. Li, J. Phys. Chem. C 114 (2010) 6553-6559.
[59] Y. Yu, G. Xiong, C. Li, F.S. Xiao, J. Catal. 194 (2000) 487-490.

[60] F.T. Fan, K.J. Sun, Z.C. Feng, H.A. Xia, B. Han, Y.X. Lian, P.L. Ying, C. Li, Chem. Eur. J. 15 (2009) 3268-3276.

[61] H.C. Xin, A. Koekkoek, Q.H. Yang, R. van Santen, C. Li, E.J.M. Hensen, Chem. Commun. (2009) 7590-7592.

[62] B. Zhang, Z. Wang, P. Ji, Y. Liu, H. Sun, W. Yang, P. Wu, Micropor. Mesopor. Mater. 179 (2013) 63-68.

[63] J.L. Gu, X. Dong, S.P. Elangovan, Y.S. Li, W.R. Zhao, T. Iijima, Y. Yamazaki, J.L. Shi, J. Solid State Chem. 186 (2012) 208-216. 